Jul 1st, 12:00 AM

\title{
Integration of Multi-Scale Dynamic Spatial Models of Socio-Economic and Physical Processes for River Basin Management
}

Hedwig Van Delden

P. Luja

Guy Engelen

Follow this and additional works at: https://scholarsarchive.byu.edu/iemssconference

Van Delden, Hedwig; Luja, P.; and Engelen, Guy, "Integration of Multi-Scale Dynamic Spatial Models of Socio-Economic and Physical Processes for River Basin Management" (2004). International Congress on Environmental Modelling and Software. 45.

https://scholarsarchive.byu.edu/iemssconference/2004/all/45

This Event is brought to you for free and open access by the Civil and Environmental Engineering at BYU ScholarsArchive. It has been accepted for inclusion in International Congress on Environmental Modelling and Software by an authorized administrator of BYU ScholarsArchive. For more information, please contact scholarsarchive@byu.edu, ellen_amatangelo@byu.edu. 


\title{
Integration of Multi-Scale Dynamic Spatial Models of Socio-Economic and Physical Processes for River Basin Management
}

\author{
Hedwig van Delden, Patrick Luja and Guy Engelen \\ Research Institute for Knowledge Systems bv, Maastricht, The Netherlands \\ E-mail: hvdelden@riks.nl
}

\begin{abstract}
Policy-makers have the difficult task to intervene in a complex human-natural system. Therefore it is not enough to focus merely on the individual processes affecting a region, rather it is necessary to look at the system as a complex integral whole. Many authors have stressed the importance of integrated assessment and model integration, but only few have proposed concrete solutions for the integration of different sub-models and the use of the resulting integrated models in practice. In this paper an attempt is made to cover both topics by means of an example: the MedAction Policy Support System (PSS). This system, implemented with the GEONAMICA® application framework, incorporates both socioeconomic and physical processes, as well as strong interactions between them. It is intended to be used by technicians supporting policy-makers and planners in the fields of land degradation \& desertification, water management and sustainable farming. This paper gives insights into the individual models, the model integration and the translation of model output into policy relevant information, but it also contends that more than the technical and scientific aspects of policy support systems are important for the actual use of such a system. It therefore provides six decisive criteria determining the actual use of PSS by their intended end users and assesses the MedAction PSS accordingly. The paper concludes with some lessons learned during the development and use of the MedAction PSS and similar Decision Support Systems.
\end{abstract}

Keywords: model integration; Policy Support System; use of PSS; indicators, linking science to policy relevant information

\section{INTRODUCTION}

Policy-makers have the difficult task to intervene in a complex human-natural system. This requires addressing the system as an integral entity rather than focussing on individual processes affecting a region. Policy Support Systems (PSS) and integrated models can support technicians, planners and policy-makers confronted with problems requiring integrated approaches.

The MedAction PSS is a system developed for this purpose. It aims to apply scientific research to the support of policy-making through the construction of an integrated model based on scientific knowledge from previous EU-projects, policy measures and policy relevant indicators.

This paper will provide some insights into the individual models and their interaction, as well as into the process of translating scientific knowledge into policy relevant information. However, it will also contend that there is more to the development of a PSS than addressing the right problems, representing the right processes and visualising the results in a transparent manner.

\subsection{The MedAction PSS}

Land degradation and desertification are important issues in arid, semi-arid and dry sub-humid regions. Climate change in combination with socio-economic processes acting on the land may induce a reduction of resource potential. With a view to mitigate these problems the EC is funding among others the research project MedAction (see Acknowledgements), in which a PSS is developed with the aim of providing a support tool for policy makers confronted with land degradation and desertification in Mediterranean watersheds and regions. 
The MedAction PSS addresses three policy themes regarding regional development: land degradation \& desertification, sustainable farming and water resources. For each of these themes the main problems, goals, policy options and policy indicators have been collected, structured, and translated into a conceptual framework. A summary of the themes in relation to the policy options and indicators is presented in Table 1 . Based on this framework an integral quantitative PSS is designed and developed.

By using policy themes as a starting point for model integration and by linking the model to policy relevant indicators, the PSS is intended to support policy-makers and planners at the regional level by providing assistance in:

1. understanding the important processes in the region as well as their interactions,

2. identification of current or future problems in the river basin,

3. impact assessment of possible policy measures to mitigate the problems, and

4. evaluation of the different alternatives.

The user interface of the PSS features a system diagram (Figure 1) representing the different interacting sub-models and processes. It enables interactive access to the individual sub-models so that the user may change parameter values, visualise sub-model output and access the on-line help system which clarifies the underlying assumptions and formal definitions of the models and the data used.

The MedAction Policy Support System is generic for Mediterranean regions. A previous version of the system has been applied to the Marina Baixa

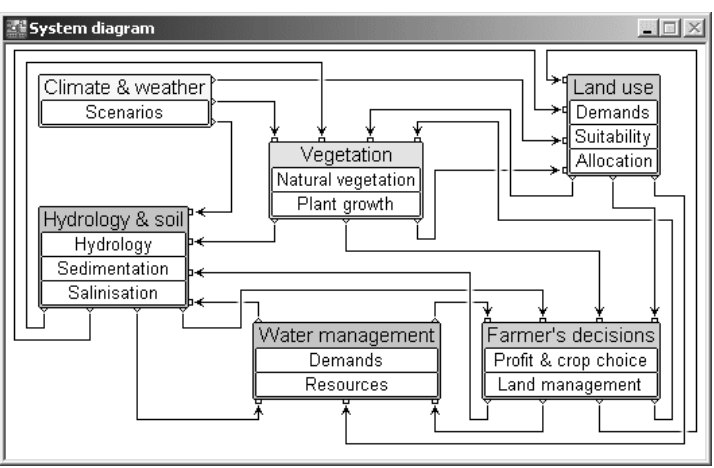

Figure 1: System diagram MedAction

Spain. It is implemented with the GEONAMICA ${ }^{\circledR}$ application framework, which enables a user to develop and run fully coupled multi-scale dynamic spatial models featuring complex feedback loops. Moreover, it provides a user-friendly interface with tools for visualisation and analysis of the outputs generated.

\section{THE INTEGRATED MODEL}

The core of the MedAction PSS consists of a number of sub-models, integrated into a single model that simulates the developments in the region for 30 years into the future.

Driving forces in MedAction are demographic and economic growth as well as climate change. The socio-economic growth is translated into demands for the different land use functions in the region. The demands are allocated dynamically in the Land use sub-models based on the spatial dynamics caused by the detailed interactions among land use functions, their dependencies on access to infrastructure, the zoning regulations restricting or facilitating particular land uses, and the physical suitability of the land to sustain the functions. For two of the land use functions, agriculture and natural vegetation, a dynamic

\begin{tabular}{|c|c|c|}
\hline The mes & Policy me asures & Indicators \\
\hline $\begin{array}{l}\text { Sustainable farming } \\
\text { Long term profits } \\
\text { Sustainable land use }\end{array}$ & $\begin{array}{l}\text { Subsidies, taxes } \\
\text { - Water price } \\
\text { Water aqailability }\end{array}$ & $\begin{array}{ll}\text { : } & \text { Profit } \\
\text { - } & \text { Crop type } \\
\text { - } & \text { Dymber and location of abandoned cells } \\
\text { - } & \text { Irrigation water used from different sources } \\
\text { - Amount and cost of irrigation water }\end{array}$ \\
\hline $\begin{array}{l}\text { Water resources } \\
\text { Availability and price of water }\end{array}$ & $\begin{array}{l}\text { - Water availability atid price } \\
\text { - Amount of water from outside the region } \\
\text { - Construction of des alinisation plants }\end{array}$ & $\begin{array}{l}\text { - Chatige in aquifer atid reservoir budget } \\
\text { - Natural water input (nunoff and techarge) } \\
\text { - Costs and amount of water used }\end{array}$ \\
\hline \multicolumn{3}{|l|}{ Laud degradation \& desertification } \\
\hline E.rosion & $\begin{array}{l}\text { - Afforestation } \\
\text { - Graxing regulations } \\
\text { - Construction of check dams } \\
\text { - Dredging }\end{array}$ & $\begin{array}{l}\text { Fertile soil depth } \\
\text { : Chosion rates } \\
\text { - Total cost of dredging }\end{array}$ \\
\hline Preservation of nature and forests & $\begin{array}{ll}\text { Afforestation } \\
\text { Zoning }\end{array}$ & $\begin{array}{l}\text { Forested area } \\
\text { Changes in natural vegetation type groups } \\
\text { Dynatric suitability maps }\end{array}$ \\
\hline Salinisation & $\begin{array}{l}\text { - Maximum amount of water available from } \\
\text { aquifer and desalinised water } \\
\text { - Maxinutu allowable percentage of salt in } \\
\text { water from desalinised }\end{array}$ & $\begin{array}{l}\text { Soil salinity } \\
\text { Salt concentration in the aquifer } \\
\text { - Restricted factor for plate growth (yes/no) }\end{array}$ \\
\hline Sustainable land use in tegion & $\begin{array}{l}\text { Zoning } \\
\text { Construction of infrastructure (dams, roads, } \\
\text { chanine1s) }\end{array}$ & $\begin{array}{ll}\text { - } & \text { Land use thap } \\
\text { Dynamic suitability maps } & \text { ESA }\end{array}$ \\
\hline
\end{tabular}

Table 1: Linking policy themes, measures and indicators

(Spain) and the Argolidas (Greece). The current version is applied to the Guadalentín river basin in suitability map is used, which changes as a result of the combined physical processes represented in 
the system: soil moisture, soil salinity, fertile soil depth, slope, and temperature. These aspects are in turn calculated in the Climate \& weather, Hydrology \& soil and Vegetation modules and are influenced by social processes such as water use and land management practices. Dynamic suitability maps are also used in one of the Farmers' decisions sub-models in which crop choices are calculated based on physical characteristics, crop price, water price and use, and social aspects influencing farmers' decisionmaking. Availability of water is calculated in the Water management module and can be experimented with by the user of the system.

\subsection{Individual models}

Decisions relative to the selection and integration of individual models are based on the availability of existing models, and the degree to which they cover the policy themes and provide support to solve problems. To a large extent use is made of models incorporated in MODULUS, the describing them will be so too. An example of this can be found in the two-step approach for calculating the detailed land use. In a first step, general land use functions (urban residential, rural residential, industry \& commercial areas, tourism, agriculture, forest reserves and natural vegetation) are allocated by means of a cellular automaton based land use model taking into consideration zoning regulations, accessibility, and suitability for the different functions. Figure $2 \mathrm{a}$ shows the land use map with these general land use classes. This type of model represents very well the land use dynamics of socio-economic functions featuring characteristic locational preferences and spatial interactions vis-à-vis one another [White and Engelen, 1997], but is less suited for modelling transitions between different crop and natural vegetation types. These are therefore handled in a second step in the Profit \& crop choice sub-model and the Natural vegetation sub-model, respectively. The Profit \& crop choice sub-model represents choices made by individual farmers relative to the use of their land. For each hectare the specific crop type is calculated based on a

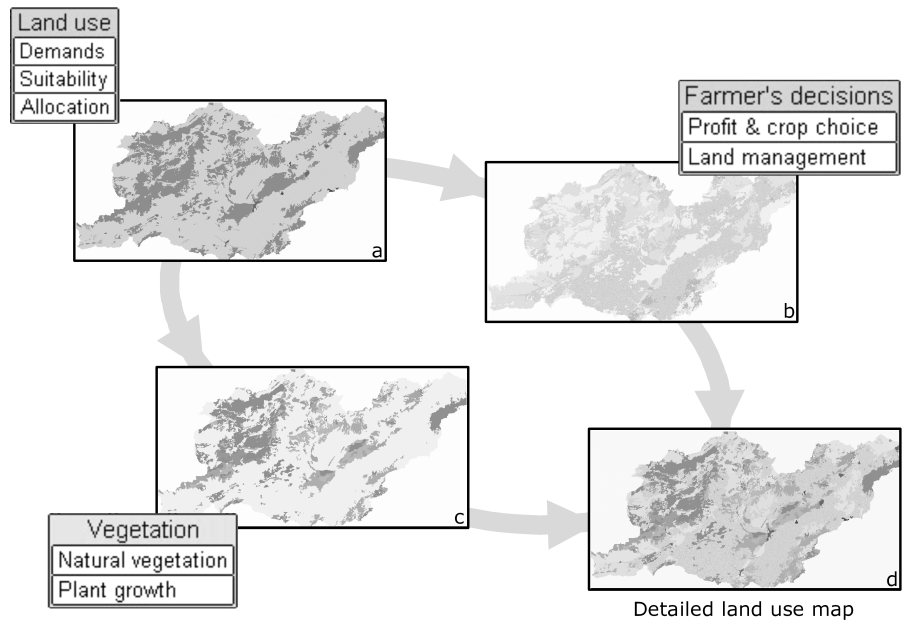

Figure 2: Two-step land use allocation

predecessor of the MedAction PSS. Selection criteria used in MODULUS as well as the modifications made to the original models are described extensively in Engelen [2003] and Oxley et al. [in press]. In the development of the MedAction PSS existing models are re-used in their original form or modified to better suit the purpose of policy-making. New models are developed to fill the gaps and missing links in the integrated system representation. For the technical integration all original models have been recoded in $\mathrm{C}++$. This turned out to be more efficient in terms of resource use and computational performance than re-using the existing code.

The individual models are designed, modified and implemented to represent the actual processes as realistically as possible. As real world processes can be very different in their nature, the models stochastic utility function considering the profit for the different crop types as well as social aspects influencing the choices made by farmers. Figure $2 \mathrm{~b}$ shows the agricultural area with the detailed crop distribution. The Natural vegetation submodel represents the transitions of the different natural vegetation types toward a climax vegetation. These transitions are partly affected by humans through herding and protection against forest fires, but are mainly based on the height and vegetation cover of the natural vegetation, which in turn are the result of physical properties like temperature, soil moisture, soil salinity and fertile soil depth. Figure $2 \mathrm{c}$ shows the location of the detailed natural vegetation types. In Figure $2 d$ the results of both steps are combined to produce a detailed map of the land uses in the region. 
Besides capturing the right types of processes the PSS represents each process at the appropriate temporal and spatial resolution. For example the Hydrology sub-model runs on a variable time step, expressed in minutes, which is required to capture the short intense rainfall events causing erosion, while the farmers' crop choice model runs on the yearly time step representing the true timing of the farmers' decision making process. The spatial resolution of the integrated models is essentially the 1 ha grid. Some minor processes are modelled at the level of the whole region.

\subsection{Model integration}

After selecting the right individual models, choices had to be made relative to their integration. The MedAction PSS has strong linkages among all its sub-models. For example the soil moisture calculated in the Hydrology sub-model is used in the Plant growth sub-model for the calculation of biomass. But biomass is in turn used for the calculation of soil moisture. There are also strong couplings between the physical and socioeconomic models. For example, the yield obtained from the Plant growth sub-model is used to calculate the crop choice in the Profit \& crop choice sub-model, and, in the Water management module replenishment obtained from the Hydrology sub-model is combined with demands from the socio-economic sub-models. growth and the physical variables, are applied to transform the model output into suitability values ranging between 0 and 1 ( 1 being very suitable, resulting in a maximal possible growth).

This is schematised in detail in Figure 3. The first column shows the maps of the important factors for plant growth calculated in the different submodels: soil moisture, soil salinity, fertile soil depth, and temperature. Since all of these submodels run on a time step smaller than one year, decisions had to be made relative to the aggregation of the model output. For the soil salinity and the fertile soil depth, the latest values are chosen, since they represent the current state of these factors. For the other two factors, soil moisture and temperature, the average is taken over the representative period for the growth of the specific plant; e.g. given that for plant type $\mathrm{Y}$ the temperature in April and May is crucial, only the average of these two months is taken into account. This results in a set of factor maps for each plant type. The second column shows the plant-specific response curves for all factors. They represent the suitability of a cell for the growth of this plant type (y-axis) as a function of its factor value (x-axis). The third column shows the result of applying the second to the first. Note that areas with low soil moisture (light coloured) are unsuitable for growth of plant type $\mathrm{Y}$ (light coloured). Areas with a higher soil moisture are more suitable, but areas that are too wet (dark coloured) result in a lower

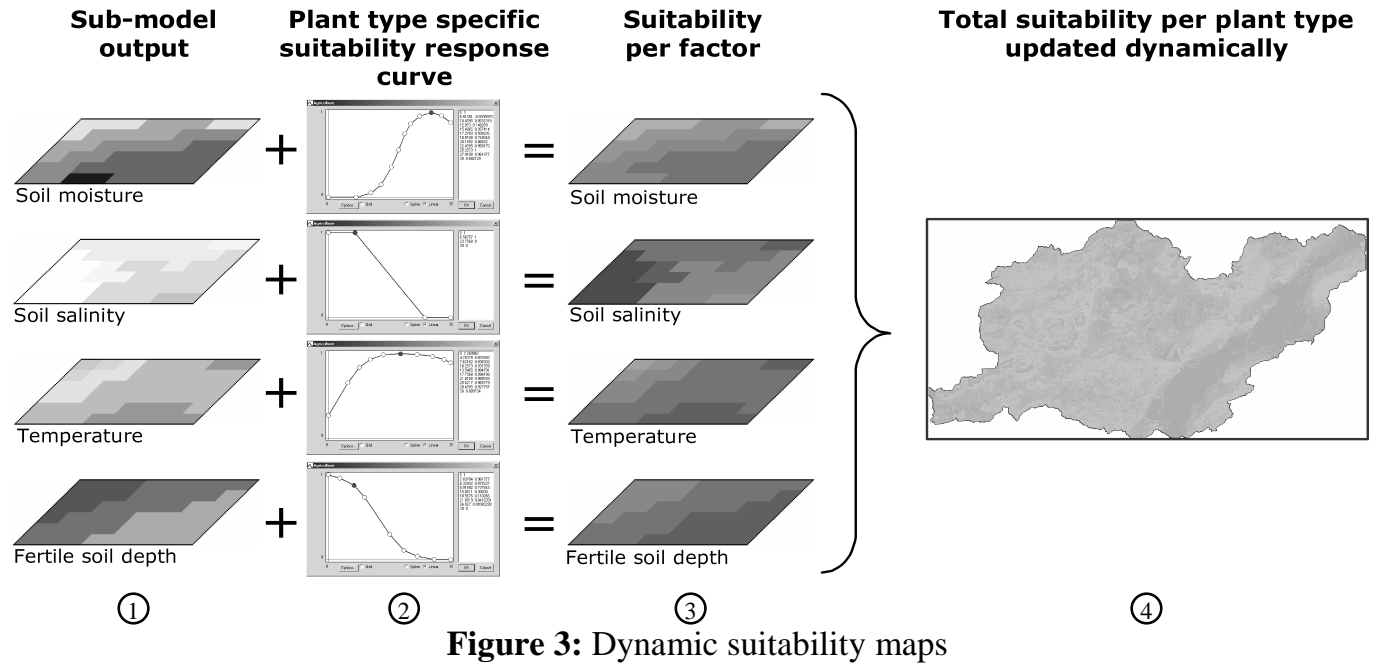

Another important linkage between the physical and socio-economic models is realised through dynamic suitability maps. They represent the physical suitability of the land for the growth of different plant types and are an input in the Land use allocation and Profit \& crop choice submodels. They are recalculated on a yearly basis using up to date model output from the physical sub-models. Response curves for the different plant types, describing the relation between plant suitability value. Finally, the suitability maps per factor are combined into a single map using a minimisation function, thus assuming that the factor with the lowest suitability restrains plant growth. 


\section{POLICY RELEVANT OUTPUT}

One of the main drawbacks of integrated models and their encompassing software systems is that they produce types and amounts of output that require an expert in all domains to be able to derive the relevant results. To assist policy-makers in overseeing and interpreting all the model output, three main aggregated indicators are developed that describe the dimensions in which the system can evolve. Each indicator covers one of the three themes of interest in MedAction:

- The Environmentally Sensitive Areas (ESA) indicator describes the desertification status of an area on the basis of some 24 aggregated physical and socio-economic variables [Kosmas et al., 1999]. In the PSS the ESA indicator is calculated dynamically and presented as a map as well as an overall figure for the whole region;

- The Water Shortage indicator describes the water shortages the socio-economic activities experience individually and as a whole, and is also presented in a map for the agricultural land-uses;

- The Farmers' Profit indicator describes the profit made by individual farmers, per crop type and for the agricultural sector as a whole.

For representing the dynamic path of the modelled system, GEONAMICA® features a threedimensional state space diagram consisting of an equilateral triangle. On each side of the triangle a different variable can be selected for representation. In the present case, the three indicators described above are represented. Initially the indicators are assumed to be in balance, therefore the system is represented as a point in the centre of the triangle (see Figure 4, $\mathrm{t}=0$ ). During a simulation exercise the indicators are recalculated yearly. Consecutive states of the system are represented by a series of new points in the state space. Figure $4, t=1$, shows a system evolving towards more severely degraded areas with decreasing water shortages and a very profitable agricultural sector. This could be the result of a warming climate with reduced precipitation in combination with expanding irrigated agriculture at the expense of dryland agriculture driven by high market prices and supported by sufficient water availability from new sources, partly from outside the region. Because of the changing climate and the resulting decrease in soil moisture, non-irrigated areas will become more degraded. Irrigated areas will become more polluted because of increased salt concentration caused by the new irrigation possibilities (assuming the salt concentration of the irrigation water will stay the same), which will lead to more environmentally sensitive areas and more severely degraded areas. Figure $4, t=2$, shows the situation a few years later when the level of land degradation causes a noticeable impact on agriculture, resulting in decreasing profits.

These two examples demonstrate the purpose and visualisation power of the state space diagram in the context of the MedAction PSS. It goes without saying that the dynamic path of the system as the result of autonomous developments, external driving forces and policy options can also be displayed, analysed and interpreted by means of this tool.

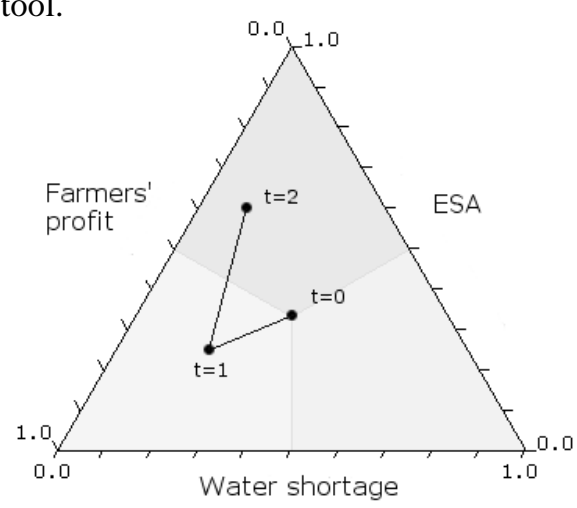

Figure 4: State space diagram

\section{DISCUSSION}

In order to understand why a PSS will or will not actually be used by the intended users in their decision-making processes, criteria are formulated in the following six questions:

- The strategy question: What is the usefulness of the system? What are the possibilities for application and what is its added value? What are the intended functions of the system (analysis, communication, knowledge management...)?

- The availability question: Is the availability of data, knowledge and models sufficient, in quality as well as quantity, to offer support? How difficult is it to obtain the necessary data, knowledge and models?

- The credibility question: Is there consensus on the models and the underlying assumptions? Can the output of the system be trusted?

- The language question: Does the system provide output that relates to the information needed by the intended end-users? Can information available to end-users be used as input into the system?

- The culture question: Are the intended endusers willing to adopt the PSS and willing and able to adjust their decision-making process? 
- The structure question: Where can the instrument be placed in the organisation? Who is going to work with the instrument and what are the actual and practical changes that have to be made?

Based on the answers to these questions, the chances for success or failure of the PSS in a particular organisation can be determined, as well as the amount of time and money that would be necessary to resolve all questions positively.

The MedAction system was developed in a research context and first had to go through phases in which the technical and scientific challenges of integration, calibration and validation could be resolved, before it could be brought to the endusers. Even though during both the MODULUS and MedAction projects there has been contact with the potential end-users, this has not been sufficient to answer all of the questions mentioned above positively. Currently the PSS scores relatively well on the more technical and scientific elements such as those concerning scientifically sound models, model integration, and visualisation tools, and it is developing into a system that can be used by policy-makers in Mediterranean regions to help answer strategic questions, assess the impacts of policy options, and translate the output of scientific models into policy relevant information. But it still needs to be brought closer to the enduser to deal with the remaining, mostly 'softer', questions. This may become possible in the near future in the form of an actual policy exercise with policy makers in the Guadalentín river basin.

\section{CONCLUSIONS AND RECOMMENDATIONS}

Developing a Policy Support System is a difficult and time consuming task. Thorough knowledge of the individual models and model integration is crucial in the development of the core of such a system-an integrated model. This paper has presented two different techniques that can be useful in model integration: the two-step land use allocation procedure, and the concept of dynamic suitability maps to link physical and socioeconomic models.

However, developing a PSS is more than developing an integrated model. The system needs to be able to support policy questions and provide policy relevant information. In the MedAction PSS this has been realised by discussing the policy themes, options and indicators with the intended end-users as a starting point for the development, so linking science to policy making.
Furthermore it is important to remember that the actual use of a policy support system depends not only on the contents of the system but also on the perceptions of the intended end-users regarding its usefulness and practicality, as well as their actual willingness to use the system. For them it is not only important that the system connects to the context of their problems but also that it relates to their decision-making process. Moreover they need to believe in the added value as well as the credibility of the system.

The MedAction PSS is developing in the right direction, but closer interaction with the intended end-users is necessary to bring it to the next level.

\section{ACKNOWLEDGEMENTS}

Research project 'MedAction: Policies to combat desertification in the Northern Mediterranean region', supported by the European Commission under contract EVK2-2000-22032: www.riks.nl/projects/medaction.

Research project 'MODULUS, A spatial Modelling Tool for Integrated Environmental Decision-Making' supported by the European Commission under contract ENV4-CT97-0685: www.riks.nl/projects/modulus.

\section{REFERENCES}

Engelen, G., Development of a Decision Support System for the integrated assessment of policies related to desertification and land degradation in the Mediterranean, p. 159195 in: Giupponi, C. and M. Shechter (eds.), Climate Change in the Mediterranean: Socio-economic Perspectives of Impacts, Vulnerability and Adaptation, Edward Elgar, Cheltenham, 2003.

Kosmas, C., M. Kirkby, and N. Geeson (eds), The Medalus project Mediterranean desertification and land use: Manual on key indicators of desertification and mapping environmentally sensitive areas to desertification, European Commission, Directorate General XII, Contract ENV4CT95-0119, Brussels, 1999.

Oxley, T., B. McIntosh, N. Winder, M. Mulligan, and G. Engelen, Integrated modelling and decision-support tools: a Mediterranean example, Environmental Modelling \& Software, in press.

White, R., and G. Engelen, Cellular automata as the basis of integrated dynamic regional modelling, Environment and Planning B: Planning and Design, 24, 235-246, 1997. 